\title{
Investigation of Risk Factors to Coronary Heart Disease in Two Countryside Villages
}

\author{
Gisleine Elisa Cavalcante da Silva ${ }^{1 *}$, Roberto Barbosa Bazotte ${ }^{1}$, Rui Curi ${ }^{2}$ and Maria \\ Angélica Rafaini Covas Pereira da Silva ${ }^{1}$ \\ ${ }^{1}$ Departamento de Farmácia e Farmacologia; Universidade Estadual de Maringá; Av. Colombo 5790; 87020-900; \\ Maringá - PR - Brazil. ${ }^{2}$ Departamento de Fisiologia e Biofisica; Universidade de São Paulo; São Paulo - SP - Brazil
}

\begin{abstract}
The aim of this study was to investigate risk factors to coronary heart disease in two countryside villages in the State of Paraná, southern Brazil, typical in terms of the poverty and lack of access to public health care. All population was invited to participate in the study. The 462 volunteers $(61.3 \%$ female, mean age $=42$ years) showed high prevalence of hypercholesterolemia (7.0\%), hypertriglyceridemia (19.0\%), hyperglycemia (11.0\%), hypertension $(30.0 \%)$ and obesity (16.0\%). The majority of the individuals, during the interview did not report the diseases detected by the testes. The results revealed that the high prevalence of hypercholesterolemia, hypertriglyceridemia, obesity, hypertension and diabetes mellitus could be consequence of the delayed detection of these diseases or inadequate treatment after diagnostic.
\end{abstract}

Key words: Hyperlipidemia, hyperglycemia, hypertension, obesity, coronary heart disease - Paraná State - Brazil

\section{INTRODUCTION}

It is well established that hyperlipidemia, type 2 diabetes mellitus, hypertension and obesity are associated with a marked increase in the risk of coronary heart disease (CHD) (Bazotte and Bertolini, 2000; Spanheimer, 2001; Kralikova et al., 1999; Despres et al., 2001). However, our knowledge of risk factors for CHD is largely derived from studies in developed countries and the applicability of these results to developing countries is not established. On the other hand, although declines in mortality rates associated with CHD have occurred in most developed countries, increases are being seen in developing countries where only a few studies about risk factors for CHD have been performed (Ounpuu et al., 2001).

In the present study, a survey of the prevalence of five traditional risk factors associated with CHD (hypercholesterolemia, hypertriglyceridemia, hyperglycemia, hypertension and obesity) were examined. For this purpose we investigated a representative sample of the urban periphery and rural Paranaense population, typical in terms of the poverty and lack of access to public health care.

\section{PATIENTS AND METHODS}

All population of Ivailândia and Sertãozinho, two villages in the southern Brazil, State of Paraná, were invited to participate in this study, approved

\footnotetext{
* Author for correspondence
} 
by ethical Committee for human studies of the State University of Maringá. The volunteers aleatory recruited were instructed to maintain their drug treatment and life habits.

At the day of the investigation blood samples were collected (7:30-9:30 a.m.) without an anticoagulant and centrifuged for the colorimetric determination of serum levels of cholesterol, triacylglycerol and glucose (Allain et al., 1974; McGowan et al., 1983; Bergmeyer and Bernt, 1974). Exclusion criteria were absence of overnight fasting or delayed blood collection (volunteers who arrived at collecting local after 9:30 a.m.). Immediately after the puncture, blood pressure was measured using mercury pressure device. Body mass index (BMI) was calculated by the formula: $\mathrm{BMI}=$ weight $(\mathrm{Kg}) /$ height $^{2}\left(\mathrm{~m}^{2}\right)$. Afterwards, information about the patient was obtained using a questionnaire. The individuals were interviewed and requested to report about food habits, physical activity, previous personal diseases, particularly hyperlipidemia, diabetes mellitus, hypertension and obesity. In addition, information about age, sex, familiar stipend, smoking habits and life stile were obtained.

Criteria for cholesterolemia $(\mathrm{mg} / \mathrm{dL})$ were: hypercholesterolemia $(>250)$, borderline (200-250) and normal $(<200)$. To triglyceridemia $(\mathrm{mg} / \mathrm{dL})$ were: hypertriglyceridemia: $(>170)$; borderline
(160-170) and normal $(<160)$. To glycemia $(\mathrm{mg} / \mathrm{dL})$ the values $>125 ; 110-125 ;<110$ were considered respectively hyperglycemia, borderline and normal. To blood pressure $(\mathrm{mm} / \mathrm{Hg})$ the volunteers were classified as hypertense $(>140 / 90)$, borderline $(130 / 80-140 / 90)$ and normal $(<130 / 80)$. To BMI $\left(\mathrm{kg} / \mathrm{m}^{2}\right)$ the subjects were classified as obese $(>30)$, borderline $(28-30)$ and normal $(<28)$. The results obtained from all exams above described were compared with the information obtained in the questionnaire.

\section{RESULTS}

The 462 volunteers were predominantly adult (mean age $=42$ years) and female $(61.3 \%)$. Poverty was prevalent since familial stipend (monthly) were U\$ 0-150 (70.6\%), 150-500 (26.9\%) and >U\$ 500 and $(2.5 \%)$. Another relevant fact was the elevated percentage of smokers in this population, i.e., $22.3 \%$. In addition, we found high prevalence of hypercholesterolemia, hypertriglyceridemia, hyperglycemia, hypertension and obesity (Table 1). However, during the interview part of the individuals (from $37.4 \%$ to $100.0 \%$ ) did not report awareness of the high or borderline values detected by the exams (Table 2).

Table 1 - Percentage of individuals (from 462 volunteers) that showed normal (N), borderline (B) or high values (H) of cholesterolemia, triglyceridemia, glycemia, blood pressure and body mass index.

\begin{tabular}{lc|r|r}
\hline & N (\%) & B (\%) & H (\%) \\
\hline Blood cholesterol & 73.0 & 20.0 & 7.0 \\
Blood triacylglycerol & 78.0 & 3.0 & 19.0 \\
Blood glucose & 80.0 & 9.0 & 11.0 \\
Mean blood pressure & 53.0 & 17.0 & 30.0 \\
Body mass index & 77.0 & 7.0 & 16.0 \\
\hline
\end{tabular}

Table 2 - Percentage of individuals (from 462 volunteers) that reported (R) or not reported (NR) previously known the diseases (borderline or high values) detected by the exams. During the interview we did not ask if the patient was obese. For this reason this parameter was omitted in the table.

\begin{tabular}{lc|c}
\hline & R (\%) & NR (\%) \\
\hline Hypercholesterolemia & 34.4 & 66.6 \\
Borderline & 23.6 & 76.4 \\
Hypertriglyceridemia & 32.1 & 67.9 \\
Borderline & 28.6 & 71.4 \\
Hyperglycemia & 32.0 & 68.0 \\
Borderline & 0 & 100.0 \\
Hypertension & 62.6 & 37.4 \\
Borderline & 22.8 & 77.2 \\
\hline
\end{tabular}




\section{DISCUSSION}

Despite increasing awareness of the growing problem of risk factors to CHD, there are few studies in Brazil (Pyolara et al., 1987; Domanski et al., 2001; Linde and Linde, 2001; Cardoso et al., 2001; Avezum et al., 1999; Pavan et al., 1999). On the other hand, although these studies have demonstrated risk factors to $\mathrm{CHD}$, to our knowledge this was the first study where the exams were associated with information obtained from interviews. The results (Table 1) showed that the high prevalence of hypercholesterolemia, hypertriglyceridemia, diabetes mellitus, hypertension and obesity typical of developed countries, also occurred in populations where poverty was prevalent (Dominiczak, 1998; Despres et al., 2001; Kralikova et al., 1999; Spanheimer, 2001).

Since part (from $37.4 \%$ to $100.0 \%$ ) of the volunteers showed anawareness of the diseases detected by their exams (Table 2), we concluded that the diagnostic occurred very late in the population investigated. Furthermore, considering that part of the individuals showed awareness of the diseases detected by the exams (Table 2), we suggested three possibilities: 1) the subjects did not start the treatment after the diagnostic, 2) abandonment of the treatment or 3) ineffective treatment after the diagnostic.

There has been overwhelming evidence that hypercholesterolemia, hypertriglyceridemia, diabetes mellitus, hypertension and obesity are closely related (Dominiczak, 1998; Despres et al., 2001; Kralikova et al., 1999; Spanheimer, 2001). For example, prospective studies have shown that obesity is a major risk factor for the development of type 2 diabetes (Klein, 2001). Moreover, type 2 diabetes is an important risk factor for hyperlipidemia and hypertension (Perez et al., 2001 ), as $75 \%$ of the patients with type 2 diabetes will eventually die from CHD (Pyolara et al., 1987). Additionally, even in the absence of obesity or type 2 diabetes, hyperlipidemia and hypertension could represent high risk to CHD (Idzior-Walus et al., 2001). In agreement with these considerations $42.0 \%$ of the subjects showed more than one of the five disturbs investigated (results not shown).

Therefore, the results from the exams associated with the information obtained from the interviews helped us to understand why the prevalence of risk factors to CHD was very high in the population investigated. Thus, we concluded that the government of the State of Paraná needed support programs for detection and treatment of risk factors for CHD. If the present conditions do not change, these could be the risk of high occurrence of CHD in this population in future.

\section{ACKNOWLEDGMENTS}

This work was supported by PRONEX (grant number 168/97).

\section{RESUMO}

O objetivo do presente estudo foi investigar os fatores de risco para doenças coronarianas em uma região pobre do Noroeste do Estado do Paraná Brasil, onde o acesso a cuidados de saúde pública é deficiente.Toda a população foi convidada a participar do estudo, sendo que a população efetivamente estudada foi de 462 indivíduos, onde a maioria era mulheres $(61,3 \%)$ com idade média de 42 anos. Os voluntários mostraram alta prevalência de hipercolesterolemia (7\%), hipertrigliceridemia (19\%), hiperglicemia (11\%), hipertensão $(30 \%)$ e obesidade (16\%). Foi realizada uma entrevista com cada participante do estudo, onde a maioria declarou não ter conhecimento sobre as doenças detectadas. Os resultados obtidos através dos exames laboratoriais e entrevistas mostraram que a alta prevalência de hiperlipidemia, diabetes mellitus, hipertensão e obesidade resultam da deteç̧ão tardia dessas doenças ou de tratamento inadequado após o diagnóstico.

\section{REFERENCES}

Allain, C. C.; Poon, L. S.; Chan, C. S.; Richmond, W. and $\mathrm{Fu}$, P. C. (1974), Enzymatic determination of total serum cholesterol. Clin. Chem., 20, 470-475.

Avezum, A.; Neto, J. M. R. and Piegas, L. (1999), Why do we need randomized and epidemiological studies on cardiovascular disease? Evidence-based cardiology VII. Arq. Bras. Cardiol., 72, 281-295.

Bazotte, R. B. and Bertolini, G. L. (2001), Fármacos Hipolipemiantes. In: Curi, R.; Pompéia, C.; Miyasaka, C. K. and Procópio, J. (eds.). Entendendo a gordura. Manole, Barueri. pp. 489-506. 
Bergmeyer, H. U. and Bernt, E. (1974), Determination of glucose with glucose oxidase and peroxidase. In: Bergmeyer, H. U. (ed). Methods of enzymatic analysis. New York : Verlag Chemie-Academic Press. pp. 1205-1215.

Cardoso, A. M.; Mattos, I. E. and Koifman, R. J. (2001), Prevalence of risk factors for cardiovascular disease in the Guarani-Mbya population of the State of Rio de Janeiro. Cad. Saúde Pública, 17, 345-354.

Despres, J. P.; Lemieux, I. and Prud'homme, D. (2001), Treatment of obesity: need to focus on high risk abdominally obese patients. $\mathrm{Br}$. Med. J., 24, 716-720.

Domanski, M.; Norman, J.; Wolz, M.; Mitchell, G. and Pfeffer, M. (2001), Diabetes and atherosclerosis: an epidemiological view. Hypertension, 38, 793-797.

Dominiczak, M. H. (1998), Hyperlipidemia and cardiovascular disease. Curr. Opin. Lipidol., 9, 609-611.

Idzior-Walus, B.; Mattock, M. B.; Solnica, B.; Stevens, L. and Fuller, J. H. (2001), Factors associated with plasma lipids and lipoproteins in type 1 diabetes mellitus: the EURODIAB IDDM Complications Study. Diabet Med., 18, 786-796.

Klein, S. (2001), Outcome success in obesity. Obes Res., 9, 354-358.

Kralikova, E.; Ceska, R. and Rames, J. (1999), Diet, smoking, and blood lipids in patients with combined familial hyperlipidemia. Cent. Eur. J. Public. Health, 7, 219-231.

Linde, R. and Linde, B. (2001), Lipids and risk assessment. Cardiol. Rev., 9 : (6), 348-358.

McGowan, M. W.; Artiss, J. D.; Strandbergh, D. R. and Zak, B. A. (1983), Peroxidase coupled method for the colorimetric determination of serum triglycerides. Clin. Chem., 29, 538-542.

Ounpuu, S.; Negassa, A. and Yusuf, S. (2001), Interheart: A global study of risk factors for acute myocardial infarction. Am. Heart J., 141, 711-721.

Pavan, L.; Casiglia, E.; Braga, L. M.; Winnicki, M.; Puato, M.; Pauletto, P. and Pessina, A. C. (1999), Effects of a traditional lifestyle on the cardiovascular risk profile: the Amondava population of the Brazilian Amazon. Comparison with matched African, Italian and Polish populations. J. Hypertens., 17, 749-756.
Perez, L. H.; Gutierrez, L. A.; Vioque, J. and Torres, Y. (2001), Relation between overweight, diabetes, stress and hypertension: a case-control study in Yarumal-Antioquia, Colombia. Eur. J. Epidemiol., 17, 275-280.

Pyolara, K.; Laakso, M. and Uusitupa, M. (1987), Diabetes and atherosclerosis: an epidemiological view. Diabetes Metab. Rev., 3, 463-524.

Spanheimer, R. G. (2001), Reducing cardiovascular risk in type 2 diabetes. Which factors to modify first? Postgrad Med., 109, 26-30.
Received: August 06, 2002; Revised: May 06, 2003; Accepted: March 03, 2004. 